\title{
Filter paper sampling of blood for the detection of antibodies to I nfectious Bursal Disease virus using a commercial ELI SA kit
}

\author{
Tofayel Ahmed ${ }^{1}$, Md Bashir Uddin², Md Rafiqul Islam³, Syed Sayeem Uddin Ahmed ${ }^{4,5}$,
} J oyita Basu', Mohammad Mejbah Uddin ${ }^{6}$

1. Veterinary Surgeon, Department of Livestock Services, Fulpur Upazilla, Mymensingh, Bangladesh 2. Sylhet Agricultural University, Faculty of Veterinary and Animal Science, Department of Medicine and Surgery, Sylhet-3100, Bangladesh 3. Bangladesh Agricultural University, Faculty of Veterinary Science, Department of Pathology, Mymensingh-2202, Bangladesh 4. Chittagong Veterinary and Animal Sciences University, Faculty of Veterinary Medicine, Department of Medicine and Surgery, Chittagong-4202,

Bangladesh 5. University of Copenhagen, Faculty of Life Sciences, Department of Large Animal Sciences, Frederiksberg C, Denmark 6. Chittagong Veterinary and Animal Sciences University, Faculty of Veterinary Medicine, Department of Anatomy and Histology, Chittagong-4202, Bangladesh 7. Kagoshima University,

Faculty of Agriculture, Department of Veterinary Clinical Sciences, Kagoshima 890-0065, Japan

Corresponding author: Mohammad Bashir Uddin, email: bashir_vet@yahoo.com

Received: 14-11-2011, Accepted: 09-12-2011, Published Online: 10-03-2012

doi: $10.5455 /$ vetworld.2012.341-345

\begin{abstract}
Aim: The present study was designed to investigate the feasibility of the filter paper sampling of blood for the detection of IBDV antibodies in chicken sera using a commercial ELISA kit.

Materials and Methods: Optimum dilution for filter paper extracts that would give a result equivalent to that of the corresponding serum sample in a commercial ELISA was determined. Correlation between the filter paper extracts based ELISA and conventional serum based ELISA was also examined and the reproducibility of the filter paper extracts based ELISA was tested.

Results: A very good correlation $(\mathrm{r}=0.9 ; \mathrm{n}=15 ; \mathrm{p}<0.01)$ was observed between the results obtained with filter paper extracts based ELISA and serum based ELISA. The antibody titre determined by two systems were very close and did not exceed more than a two-fold dilution with the exception of samples having very low antibody levels, where relatively higher background reaction was observed with filter paper extracts based ELISA. The filter paper extracts based ELISA appeared to be quite reproducible with a coefficient of variation less than $10 \%$.

Conclusion: Filter paper based ELISA could be a useful alternative to serum dependant ELISA assays for sero-profiling chicken flocks for IBDV antibodies.

Key Words: Filter paper extract based ELISA, IBD, Serum based ELISA, Seroprofiling

To cite this article: Ahmed T, Uddin MB, I slam MR, Ahmed SSU, Basu J, Uddin MM (2012) Filter paper sampling of blood for the detection of antibodies to Infectious Bursal Disease virus using a commercial ELISA kit, Vet World
\end{abstract} 5(6):341-345, doi: 10.5455/vetworld.2012.341-345

\section{I ntroduction}

Poultry industry is a rising sector in Bangladesh but the development of this sector is often interrupted by frequent outbreaks of a number of emerging and recurrent diseases. One of the most important diseases of commercial poultry is infectious bursal disease (IBD). It is an acute, highly contagious immunosuppressive viral infection of chickens [1,2,3]. Among poultry diseases in Bangladesh, IBD is the number one killer causing up to $80 \%$ mortality in field outbreaks $[4,5,6,7]$.

Vaccination is the only means for the prevention of IBD but vaccination failure is quite common due to various factors such maintenance, storage or inadequate immune response following vaccination or neutra- lization of vaccine virus by the maternal antibodies present in chicks. Therefore, maternal antibody levels in chicks should be determined before vaccination. The enzyme-linked immunosorbent assay (ELISA) is commonly used and considered to be the easiest method for measuring maternal antibody levels against IBDV [8]. The commercial IBDV ELISA kits are available through an ELISA assay for detecting antibodies to IBDV also has recently been developed locally.

Conventionally, serum obtained from blood is used in ELISA, but it is often difficult to collect sufficient blood from very young chicks without killing the birds. As an alternative, a technique has been developed for sampling blood on filter paper, where a small drop of blood is soaked on a filter paper 
Table-1. Similarities between absorbance values of sera samples (1: 500 dilutions) and corresponding filter paper extracts ( serial two-fold dilutions)

\begin{tabular}{|c|c|c|c|c|c|c|c|c|c|c|c|}
\hline \multirow[t]{2}{*}{ Sample } & \multirow{2}{*}{$\begin{array}{l}\text { Serum } \\
(1: 500)\end{array}$} & \multicolumn{8}{|c|}{ Filter paper extracts } & \multicolumn{2}{|c|}{$\begin{array}{l}\text { Corresponding dilution of } \\
\text { Filter paper extracts } \\
\text { expected to vive } \\
\text { absorbance similar to that } \\
\text { 1:500 dilution of Serum }\end{array}$} \\
\hline & & $(1: 2)$ & $(1: 4)$ & $(1: 8)$ & $(1: 16)$ & $(1: 32)$ & $(1: 64)$ & $(1: 128)$ & $(1: 256)$ & $\begin{array}{l}\text { Dilution } \\
\left(\log _{2}\right)\end{array}$ & $\begin{array}{l}\text { Geometric mean } \\
\text { dilution }\left(\log _{2}\right)\end{array}$ \\
\hline
\end{tabular}

strip, which can be later extracted with PBS and used in ELISA [9]. Filter paper extracts based ELISA has been successfully used to detect antibodies to foot and month disease virus [10], rinderpest virus [11, 12], duck plague virus [13] and Pasteurella multocida [14].

However, there is no study about filter paper based ELISA for the detection of antibody to IBDV using commercial kits. Therefore, the present study was designed to investigate the feasibility of the filter paper sampling of blood for the detection of IBDV antibodies in chicken sera using a commercial ELISAkit.

\section{Materials and Methods}

Sampling and sera collection: The study was performed during the period of January - June, 2004. Blood samples were obtained from chickens, which were reared in the Department of Pathology, Bangladesh Agricultural University. The chicks were vaccinated against infectious bursal disease virus with a commercial vaccine "Nobilis D-78" (Intervet, the Netherlands) at 14 days of age. Blood samples from 4 birds were obtained at day old, then at 4, 6 and 8 weeks of age, respectively either from the jugular vein during slaughter (day old chicks) or from the wing vein. The $100 \mu \mathrm{l}$ of blood samples were soaked scientifically and aseptically on commercially available Whatman filter paper no.1 ( $2 \mathrm{~cm} \times 5 \mathrm{~cm} \times 0.3 \mathrm{~mm})$ and allowed to dry at room temperature away from direct sun light after that stored in screw-capped air tight vessels at $-20^{\circ} \mathrm{C}$ for subsequent extraction in Dulbecco's phosphate buffer saline and used in filter paper based ELISA.

Blood samples were also collected in vials and allowed to clot at room temperature at slanting position in order to obtain serum. The separated serum was collected in fresh vials and clarified by low speed centrifugation ( $3000 \mathrm{rpm}$ for 15 minutes) then stored frozen at $-20^{\circ} \mathrm{C}$ until used. Five discs cut out from each blood soaked filter paper strips with a paper punch were extracted with $300 \mu 1 \mathrm{PBS}$ for 60 minutes at room temperature.

A commercial ELISA kit (Infectious Bursal Disease Antibody Test Kit-IDEXX Laboratory, Inc., Westbrook, Maine 04092, USA) was used. The test was used and the test performed as described by the manufacturer. The frozen sera samples were thawed. Five hundred fold (1:500) dilution of sera samples were made in sample diluent. The Filter paper extracts were used immediately after extraction. Filter paper extracts were diluted either serially in two-fold dilutions or at an appropriate fixed dilution (1:5). This was done in the same laboratory, BAU. The optical density (OD) or absorbance values were determined at 650 micron using an ELISA reader (SPECTERA max 340 pc, Molecular Devices Inc., USA) at the Surgery and Obstetrics Department of Bangladesh Agricultural University.

Negative control mean, positive control mean, sample to positive $(\mathrm{S} / \mathrm{P})$ ratio and endpoint titres were calculated. Sera samples with $\mathrm{S} / \mathrm{P}$ ratios of less than or equal to 0.2 were considered negative and S/P ratios greater than 0.2 (titre greater than 396) were considered positive.

Optimum dilution for filter paper extracts: To determine the optimum dilution for filter paper extracts, the ELISA was performed using five selected sera samples at 1:500 dilution and their corresponding filter paper extracts at two-fold serial dilutions ranging from 1: 2 up to $1: 256$.

The absorbance values for the dilution of each filter paper extracts giving an absorbance value close to that of 1: 500 dilution of the corresponding serum sample was determined (Table 1).

Comparison of ELISA results based on sera and filter paper extracts: A total of 15 sera and corresponding filter papers extracts were tested at dilutions of 1:500 and 1:5 accordingly. The antibody titre 
Filter paper sampling of Blood for the detection Antibodies to IBDV using a Commercial ELISA Kit

Table-2. The ELI SA absorbance values and antibody titer of 15 sera samples (1: 500 dilution) and corresponding filter paper extracts ( $1: 5$ dilution)

\begin{tabular}{|c|c|c|c|c|c|}
\hline \multirow{2}{*}{\multicolumn{2}{|c|}{ Sampling occasion Sample }} & \multicolumn{2}{|c|}{ Mean absorbance } & \multicolumn{2}{|c|}{ Mean predicted titre } \\
\hline & & Serum 1: 500 & Filter paper extract 1: 5 & Serum 1: 500 & Filter paper extract 1: 5 \\
\hline \multirow[t]{2}{*}{ I } & 1 & 0.385 & 0.357 & 3889 & 3525 \\
\hline & 3 & 0.543 & 0.538 & 5989 & 5922 \\
\hline \multirow[t]{2}{*}{ II } & 1 & 0.072 & 0.178 & 107 & 1289 \\
\hline & 2 & 0.069 & 0.12 & 78 & 617 \\
\hline \multirow[t]{4}{*}{ III } & 1 & 0.479 & 0.602 & 5130 & 6791 \\
\hline & 2 & 0.364 & 0.472 & 3616 & 5036 \\
\hline & 3 & 0.287 & 0.426 & 2630 & 4427 \\
\hline & 4 & 0.234 & 0.389 & 1968 & 3941 \\
\hline \multirow[t]{2}{*}{ IV } & 1 & 0.424 & 0.488 & 4400 & 5250 \\
\hline & 2 & 0.549 & 0.611 & 6070 & 6914 \\
\hline
\end{tabular}

against IBDV in these two systems were calculated and compared by correlation-regression analysis.

Inter-assay variability: For determining the interassay variability between ELISA performed using sera and filter paper extracts respectively, replicate filter paper and blood samples were collected from each of the 25 week old birds $(n=5)$ and tested at dilutions explained above. Inter-assay co-efficient of variation (CV) was calculated for each bird.

\section{Results}

In this study, filter paper sampling of blood was adopted for detection of IBDV antibodies in chicken sera using a commercial ELISA kit.

Determination of optimum dilution for filter paper extracts: After analysis it was found that, the absorbance value of each serum sample at 1: 500 dilution matched closely to the absorbance value (or Optical Density) of the filter paper extracts at a dilution between $1: 2$ and $1: 8$.

The exact corresponding dilution of the filter paper extracts expected to give an absorbance value equal to that given by the 1:500 dilution of the serum was also calculated by correlation-regression analysis. The geometric mean of the calculated corresponding filter paper extracts dilutions was found to be $\log _{2} 2.3$, which is equal to 4.92 . Therefore, a filter paper extract dilution of 1: 5 was considered to be equivalent to 1 : 500 dilution of the serum.

Comparison of ELI SA results based on sera and filter paper extracts: For comparison of ELISA results based on sera and filter paper extracts, the ELISA was performed using 15 serum samples at 1 :
500 dilution, collected on 4 different occasions and their corresponding filter paper extracts at 1:5 dilution. The absorbance values and calculated titres are presented in Table 2.

The antibody titres determined by two systems were very close and did not exceed more than a twofold dilution, with the exception of occasion II. The correlation between the ELISA titres determined from the serum and filter paper extracts were analysed by correlation regression analysis. There was a very strong positive correlation $(\mathrm{r}=0.9 ; \mathrm{n}=15 ; \mathrm{p}<0.01)$. The results are shown in Figure 1.

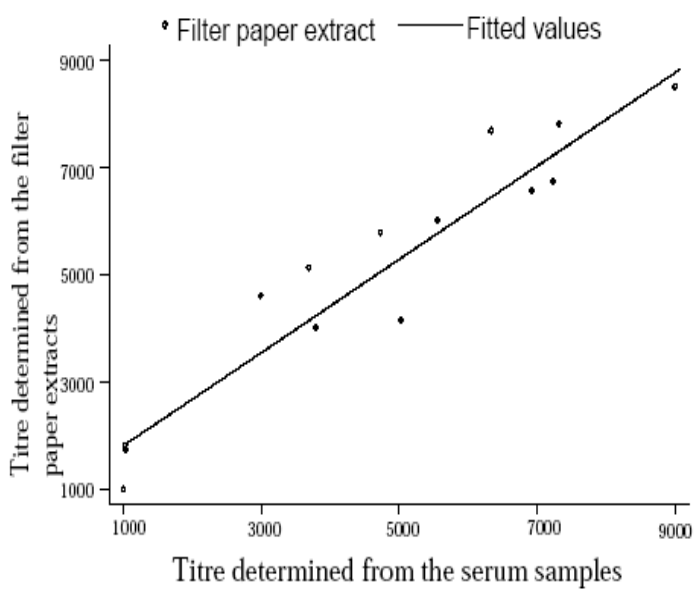

Figure-1. Correlation between ELISA titres determined from the serum and filter paper extract

Inter-assay variability: Sera and filter paper extracts antibody titres, Mean $\pm \mathrm{SD}$ and $\% \mathrm{CV}$ are shown in Table 3. The coefficient of variation obtained from this study was less than $10 \%$. 
Filter paper sampling of Blood for the detection Antibodies to IBDV using a Commercial ELISA Kit

Table-3. Percent coefficient of variation (CV) of ELI SA titres determined from 5 replicate samples of each of 5 birds

\begin{tabular}{|c|c|c|c|c|c|c|c|c|}
\hline \multirow[t]{3}{*}{ Sample } & & \multicolumn{7}{|c|}{ Antibody titre } \\
\hline & \multirow[t]{2}{*}{ Serum $(1: 500)$} & \multicolumn{5}{|c|}{ Filter paper extracts $(1: 5)$} & \multirow[b]{2}{*}{ Mean \pm SD } & \multirow[b]{2}{*}{$\% \mathrm{CV}$} \\
\hline & & a & b & c & d & e & & \\
\hline $\begin{array}{l}1 \\
2 \\
3 \\
4 \\
5\end{array}$ & $\begin{array}{c}12565 \\
13786 \\
12093 \\
9337 \\
13320\end{array}$ & $\begin{array}{l}18378 \\
15515 \\
12837 \\
8322 \\
13522\end{array}$ & $\begin{array}{l}16520 \\
15005 \\
11274 \\
8186 \\
13543\end{array}$ & $\begin{array}{l}16870 \\
15976 \\
11056 \\
8653 \\
14272\end{array}$ & $\begin{array}{l}15005 \\
15761 \\
10916 \\
8148 \\
14516\end{array}$ & $\begin{array}{l}15515 \\
16253 \\
10203 \\
8770 \\
14171\end{array}$ & $\begin{array}{l}16458 \pm 1310 \\
15702 \pm 475 \\
11257 \pm 970 \\
8416 \pm 281 \\
14005 \pm 449\end{array}$ & $\begin{array}{l}7.96 \\
3.03 \\
8.62 \\
3.33 \\
3.21\end{array}$ \\
\hline
\end{tabular}

\section{Discussion}

The whole blood dried on filter paper as an alternative to serum has been used previously in ELISA for detecting antibodies to foot and mouth disease virus [10], Rinderpest virus [11, 12] Duck plague virus [13] anaplasma [14] Pasteurella multocida [15] and Schistosome [9]. Although no report is available on the use of filter paper extract to detect antibodies-to IBDV by ELISA [16] used filter paper extract for detecting IBDV by antibodies by agar gel precipitation test. The difference was significant between serum samples and filter-paper eluates in which supports the present findings.

The filter paper extracts based assay used in the present study with a commercial ELISA kit that is routinely used in between poultry industry for measuring maternal antibody levels, in chicks to predict the optimum time for vaccination. The kits are validated for use on sera samples. However, it is often quite difficult to obtain sufficient blood from young chicks due to their small size. The study proposes the filter paper sampling technique and extracts usage as an alternative to bleeding relatively large volumes of blood and sera testing in the commercial assay. The filter paper extracts can be used in the ELISA protocol recommended by the kit manufacturer without any modification except that the extracts should be further diluted 1:5 in the sample diluent instead of the 1:500 recommended for sera samples. This finding is in partial agreement with that of Evengard and Linder [9] who observed that 1:5 dilution of filter paper extracts were equivalent to 1: 400 dilution of corresponding serum sample in bovine of schistosome-specific antibodies. The variation could be due to species differences or differences in the filter paper extraction procedures.

A very good correlation $(r=0.9 ; n=15 ; p<0.01)$ was observed between the results obtained with the filter paper extracts and serum based ELISA in the present study respectively. The antibody titre determined by two systems were very close and did not exceed more than a two-fold dilution, with the exception of one particular sampling occasion (Occasion II). In fact, at that particular occasion the birds had very low levels of antibodies (having the titre between 78 to 107 with serum based ELISA). However, with filter paper based ELISA the antibodies were between 617 and 1361. This discrepancy would suggest that at very low antibody levels, the filter paper extracts based ELISA might give relatively a high background reaction. Further studies are required in this regard. One possible option is to extract the blood soaked filter paper in sample diluent instead of PBS to reduce nonspecific binding.

Besides the drawback mentioned above, the filter paper based ELISA appeared to be quite reproducible with a coefficient of variation less than $10 \%$. Heller [11] also suggested that the accuracy and precision of filter paper extract based ELISA were excellent with a sensitivity of $100 \%$ and specificity of $98.26 \%$.

The major limitation of the present study was the small sample size for determination of the optimum dilution of filter paper extracts and for comparison of the filter paper extracts based ELISA and serum based ELISA. This was due to the resource constraint as only one kit (5 antigen-coated plates) was available for the study.

\section{Conclusion}

Filter paper based ELISA could be a useful alternative to serum dependant ELISA assays for seroprofiling chicken flocks for IBDV antibodies.

\section{Acknowledgements}

This research work was conducted during the period of January -June, 2004 as the part of MS. The first author (as MS student) humbly desires to express his deepest gratitude to his MS supervisors. The authors would like to thanks to all respondents of the study areas. 
Filter paper sampling of Blood for the detection Antibodies to IBDV using a Commercial ELISA Kit

\section{Competing interests} interests.

The authors declare that they have no competing

\section{References}

1. Lukert, P.D. \& Saif, Y.M., (1997). "Infectious bursal disease virus." In: Calnek BW, Barnes HJ, Beard CW, McDougald LR, Saif YM (eds.). Diseases of Poultry, Ames: Iowa State University Press, 721-738.

2. McFerran, J.B., (1993). Infectious bursal disease. In: Virus. McFerran JB, McNulty MS (eds.). Infections of birds, Elsevier Science Publishers, Amsterdam, 213-228.

3. Muller, H., Islam, M.R. \& Raue, R., (2003). Research on infectious bursal disease the past, the present and the future (Review). Veterinary Microbiology, 97: 153-165.

4. Chowdhury, E.H., Islam, M.R., Das, P.M., Dewan, M.L. \& Khan, M.S.R., (1996) Acute infectious bursal disease in chickens: pathological observation and virus isolation. Asian-Aust. J. Anim. Sci, 9: 465-469.

5. Islam, M.R., Das, P.M., Chowdhury, E.H. \& Dewan, M.L., (1994a) Very virulent infectious bursal disease virus: a challenge for poultry industry in Bangladesh. Paper presented in the 12th Annual Conference of Bangladesh Society of Microbiologists, BARC, Dhaka, January 19 and February 11.

6. Islam, M.R., Das, P.M., Chowdhury, E.H. \& Dewan, M.L., (1994b) Some observations on infectious bursal disease of chickens reproduced experimentally with a highly virulent local isolate. Paper presented in the 18th Bangladesh Science Conference, Bangladesh Agricultural University, Mymensingh, 22-24 June.

7. Rahman, M.M., Hossain, W.I.M.A., Rahman, M.M., Mia, A.H. \& Biswas, M.R.H., (1996) Isolation and Identification of Infectious bursal disease virus in chickens in Bangladesh. Bang. Vet. J, 30:7-11.

8. Snyder, D.B., Marquardt, W.W., Mallinson, E.T., Russek-Cohen, E., Savage, P.K. \& Allen, D.C., (1986) Rapid serological profiling by enzyme linked immunosorbant assay. IV. Association of Infectious bursal disease serology with broiler flock performance. Avian Dis, 30: 139-148.

9. Evengard, B., Hagi, H. \& Linder, E., (1988) A filter paper technique for the detection of IgG and IgM class schistome-specific antibodies in an endemic area.Ann. Trop. Med. Parasitol, 82: 307-309.

10. Armstrong, R.M., Crowther, J.R. \& Denyer, M.S., (1991) The detection of antibodies against foot-andmouth disease virus (FMDV) in filter paper eluates from pig sera or whole blood by ELISA. J. Virol. Methods, 34: 181-192.

11. Heller, C., Stem, C., Wamwayi, H. \& Grieve, A., (1988) Development of a filter paper based ELISA for rinderpest antibodies. Vet. Rec, 142: 729.

12. Ramadass, P., Ganesan, P.I., Meerarani, S. \& Padmanaban, V.D., (1993) Usefulness of filter paper ELISA for detection of rinderpest antibodies. Indian Vet. J, 70: 795-797.

13. Malmarugan, S., Sulochana, S., Verma, R., Sharma, N., Varma, T.K., Bagherwal, R.K. \& Jaisal, T.N., (2000) Comparison of whole blood dried on filter paper and conventional serum for detection of antibodies to duck plague virus by enzyme linked immunosorbant assay (ELISA). Advancements in Veterinary Science. Indian Veterinary Congress, Izatnagar, India, 215-219. www.iaavr.org.

14. Ssenyonga, G.S.Z., Montenegro, J.S., Kakoma, I. \& Mansen, R., (1993). A comparative study of the use of dried blood on filter papers and serum samples for serodiagnosis of anaplasmosis. Ug. J. Agric. Sci, 1:1-3.

15. Natalia, L. \& Priadi, A., (1998) The use of filter paper for collecting samples for immunodiagnosis of Pasteurella multocida infection: analysis and comparison of the protein composition of filter paper extracts and serum. Journal Ilmu Ternak dan Veteriner, 3: 182-187.

16. Roy, P., Nachimutu, K., Venugopalan, A.T., Dorairajan, N., Purushothaman, V. \& Koteeswaran, A., (1994) Filter paper technique for seromonitoring against Infectious bursal disease. Trop. Anim. Helth. Prod, 26: 251-252. 